\title{
Correlative study of FNAC and histopathology for breast lesions
}

\author{
Sreedevi CH, ${ }^{1}$ K Pushpalatha ${ }^{2}$ \\ ${ }^{1}$ Dr. Sreedevi CH, Assistant Professor, ${ }^{2}$ Dr. K Pushpalatha, Associate Professor, both authors are affiliated with \\ Maheshwara Medical College, Chitkul (V), Near Isnapur X Roads, Patancheru, Medak District, Telangana 502307, India
}

Address for Correspondence: Sreedevi CH, Assistant Professor, Maheshwara Medical College, Chitkul, E-mail: co.gemsap@yahoo.com

\begin{abstract}
Introduction: Fine needle aspiration cytology has become increasingly popular in diagnosis of palpable breast masses as it is sensitive, specific, expedient, economical and safe for screening of breast lesions. It has high sensitivity and specificity. The aim of the study was to categorize breast lesions and correlate the fine needle aspiration cytology diagnosis with histo-pathological findings. Methods: A Two years study was carried out on female and male patients with age 10-72, who visited hospital with complaint of breast lump, pain in the breast or discharge from the nipple. Results: Tumors on right breast is higher in percentage (54\%) and 66\% of tumors are less than $6 \mathrm{~cm}$ in size. Two cases, which found to be malignant with FNAC have become benign in biopsy test. Conclusion: The current study initiated to find the effectiveness of this technique and compared with biopsy methods.
\end{abstract}

Key words: Breast lesions, Biopsy, Fine needle aspiration cytology, Breast cancer

\section{Introduction}

Breast cancer is the most common cancer among women in the western world and 2 nd most in India after carcinoma cervix. The incidence of the disease has shown a steep rise in women younger than 40 years of age. Only less than $50 \%$ women are alive and free of disease for 10 years after the diagnosis [1]. Various methods have been developed to evaluate the breast lesions with a goal of identifying a sensitive, specific, economical and efficient technique for the diagnosis of breast cancer. Physical examination, FNAC, mammography, ultrasound, core needle biopsy and open excision biopsy are used for diagnostic workup of a palpable breast mass. Various combinations of these methods have been also used to diagnose the lesions effectively. FNAC (Fine Needle Aspiration Cytology) is a popular diagnostic technique as it can be done in the first visit without the need of anaesthesia. This technique is commonly used in combination with physical examination and mammography, so called triple-test diagnostic triad [2]. We have studied the effectiveness of this technique and compared with biopsy methods. Accuracy in the diagnosis can be increased by multiple sampling of appropriate sites by

Manuscript received: $18^{\text {th }}$ November 2016

Reviewed: $27^{\text {th }}$ November 2016

Author Corrected: $05^{\text {th }}$ December 2016

Accepted for Publication: $12^{\text {th }}$ December 2016
Ultrasonography guidance and / or mammographic localization. That is why FNAC is regarded as preliminary diagnostic procedure, as a screening procedure with or without Ultrasonography or stereotactic guidance, or as a follow-up procedure for post mastectomy or lumpectomy [3]. Fine Needle Aspiration Cytology can also use to diagnose lesions of male breasts such as gynaecomastia and carcinoma, accessory axillary breasts and their lesions, and status of the axillary lymph nodes. Thus the FNAC have reduced the number of open breast biopsies. The aim of this study was to find out the common causes of breast lump and to find out sensitivity and specificity of FNAC of breast lump in our institute.

\section{Materials and Methods}

Study setting: The present study was carried out in department of Pathology, Maheshwara Medical College, Chitkul, Sangareddy.

Participants: The patients with palpable breast lump referred from general surgery department in the institution for FNAC were involved in the study after obtaining written informed consent. Consent was taken after due explanation of the procedure and its benefit to 


\section{Research Article}

the patients. The study was approved by institutional ethical committee.

Data collection- The case history of the patient was recorded, includes detail history of pain, nipple discharge, ulceration of nipple and duration of lesion. The examination of breast lump was done with recording of size and site of lump, consistency, and fixation to skin and underline tissue, retraction of nipple along with regional lymph node involvement. The skin over the breast was wiped with antiseptic solution and spirit, suspected lesion was held with one hand in a position favorable to fine needle aspiration. Procedure is done by using 20 gauze needle fitted on $10 \mathrm{ml}$ disposable syringe in Syringe Holder. When needle had entered the lump area, the piston of the syringe was retracted thus creating a vacuum with the needle in a position to move back and fro, three or more times in a different direction of the lump [4]. Throughout the procedure negative pressure was maintained in a syringe then before removing needle from the lump negative pressure is resolved. The needle withdrawn and air is filled in the syringe reconnected to the needle and material is smeared on glass slide with the help of cover glass gently. The wet smear fixed with Ether Alcohol mixture stained with Papanicolaou Stain. The air dried smear fixed in Methyl Alcohol stained with May Grunewald Geimsa stain. The smears were screened under low and high magnification and diagnosis was made as: Unsatisfactory Benign, Atypical/Indeterminate, Suspicious of malignancy or Malignant. For all the patients either open or excision biopsy was also done for histopathological confirmation.

Data analysis: Data was analysed by SPSS 20.0 . Results are expressed as frequency and percentage.

\section{Results}

The age-wise distribution for the 100 tumors selected to the study the correlation between FNAC and Biopsy for breast lesions is shown in Table 1. Tumors on right breast are higher in percentage (54\%) as shown in table 2 . Table 3 shows that $66 \%$ of tumors are less than $6 \mathrm{~cm}$ in size. Table 4 shows the comparison of FNAC and biopsy results. Two cases, which found to be malignant with FNAC have become benign in biopsy test.

Table-1: FNAC results age-wise- Malignant and benign

\begin{tabular}{|l|c|c|c|}
\hline & Benign & Malignant & Total \\
\hline 10 to 20 & 22 & 0 & 22 \\
\hline 21 to 30 & 36 & 0 & 36 \\
\hline 31 to 40 & 17 & 4 & 21 \\
\hline 41 to 50 & 8 & 4 & 12 \\
\hline 51 to 60 & 2 & 5 & 7 \\
\hline 61 to 70 & 0 & 1 & 1 \\
\hline$>70$ & 1 & 0 & 1 \\
\hline Percentage & $86.00 \%$ & $14.00 \%$ & 100 \\
\hline
\end{tabular}

Table-2: Tumor side distribution

\begin{tabular}{|c|c|c|c|}
\hline & Benign & Malignant & \% \\
\hline Right & 48 & 6 & $54.00 \%$ \\
\hline Left & 33 & 8 & $41.00 \%$ \\
\hline Bilateral & 5 & 0 & $5.00 \%$ \\
\hline
\end{tabular}

Table-3: Tumor size distribution

\begin{tabular}{|c|c|c|c|}
\hline Size in cms & Benign & Malignant & \% \\
\hline$<5 \mathrm{cms}$ & 63 & 4 & $67.00 \%$ \\
\hline 5 to $10 \mathrm{cms}$ & 23 & 10 & $33.00 \%$ \\
\hline$>10 \mathrm{cms}$ & 0 & 0 & $0.00 \%$ \\
\hline
\end{tabular}


Research Article

Table-4: Comparison of FNAC and Biopsy results

\begin{tabular}{|l|c|c|c|c|c|c|}
\hline & $\begin{array}{c}\text { Fibroadeno } \\
\text { ma }\end{array}$ & $\begin{array}{c}\text { Fibroadeno } \\
\text { sis }\end{array}$ & $\begin{array}{c}\text { Fibrocys } \\
\text { tic } \\
\text { disease }\end{array}$ & $\begin{array}{c}\text { Phyllod } \\
\text { es }\end{array}$ & $\begin{array}{c}\text { Gynecomasti } \\
\text { a }\end{array}$ & Malignant \\
\hline FNAC & 58 & 13 & 10 & 3 & 2 & 14 \\
\hline Biopsy & 59 & 14 & 10 & 3 & 2 & $\begin{array}{c}\text { Infiltrating duct cell } \\
\text { carcinoma-10 } \\
\text { Medullary carcinoma-2 } \\
\text { Lobular carcinoma-2 }\end{array}$ \\
\hline
\end{tabular}

\section{Discussion}

In our study a total number of 100 breast tumours are selected to study the correlation between FNAC and biopsy diagnostic methods. According to FNAC 86\% are benign, however biopsy result showed 84\%. 2 malignant cases of FNAC turned to 1 case of each Fibroadenoma and Fibroadenosis [4]. FNAC and Biopsy results are consistent for Gynecomastia, Phyllodes and Fibrocystic disease. It was reported that, over all FNAC is 98\% accurate for diagnosing breast lesions and $85.7 \%$ accurate for malignant tumour diagnosis [5]. Another study has found 10 cases of gynaecomastia on FNAC [6] and have noted 70 cases of carcinoma and 295 cases of benign breast lesions amongst males [8].

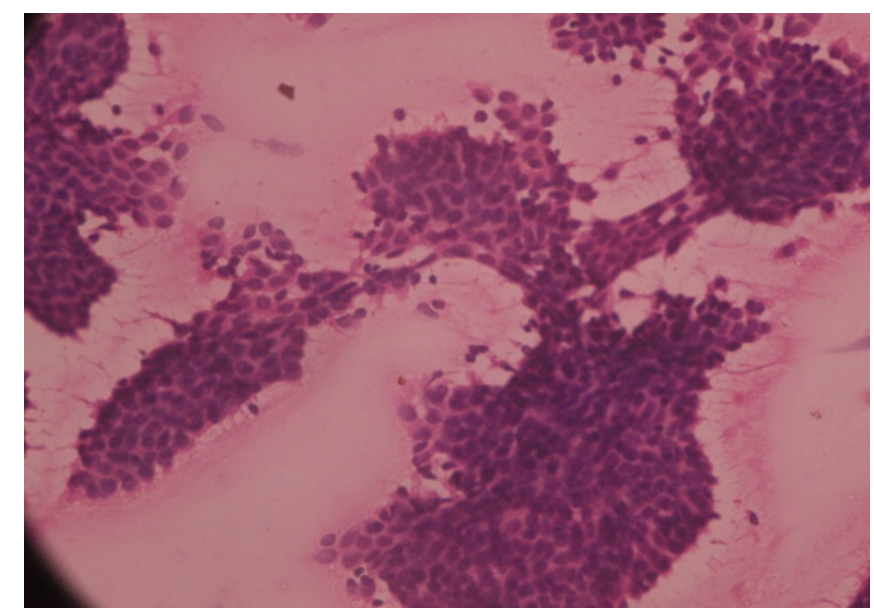

Figure-1: Fibroadenoma (FNAC)

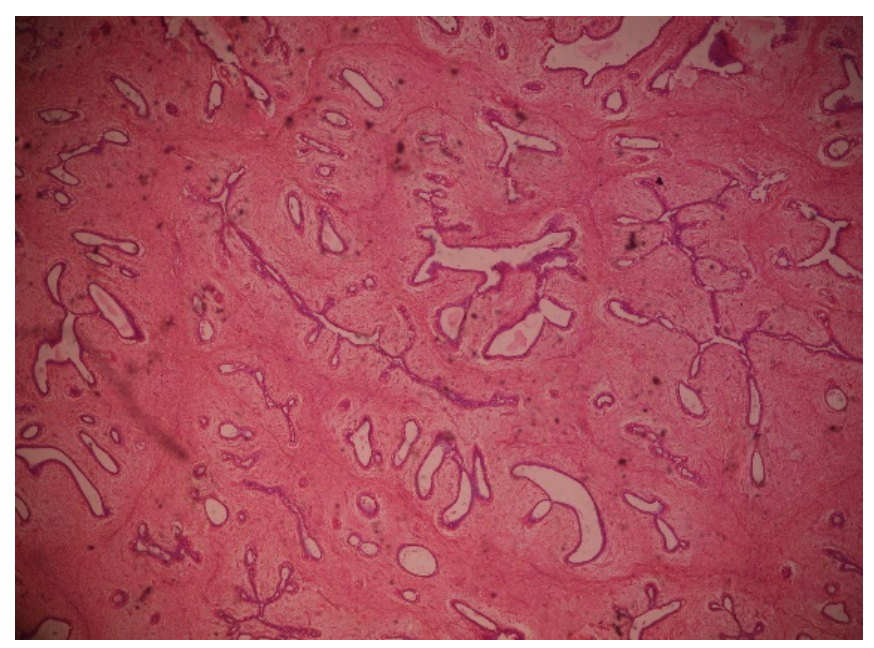

Figure-2: Fibroadenoma (Biopsy) 


\section{Research Article}

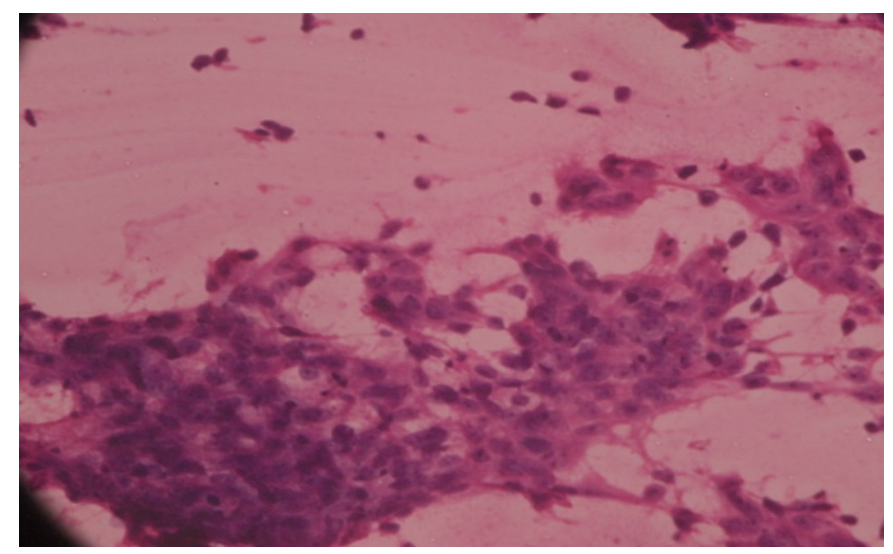

Figure-3: IDC (FNAC)

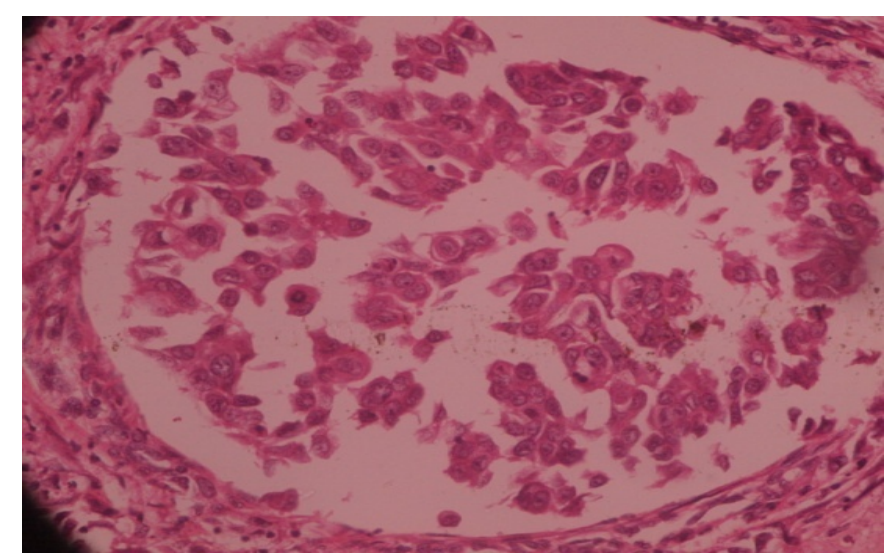

Figure-4: IDC (Biopsy)

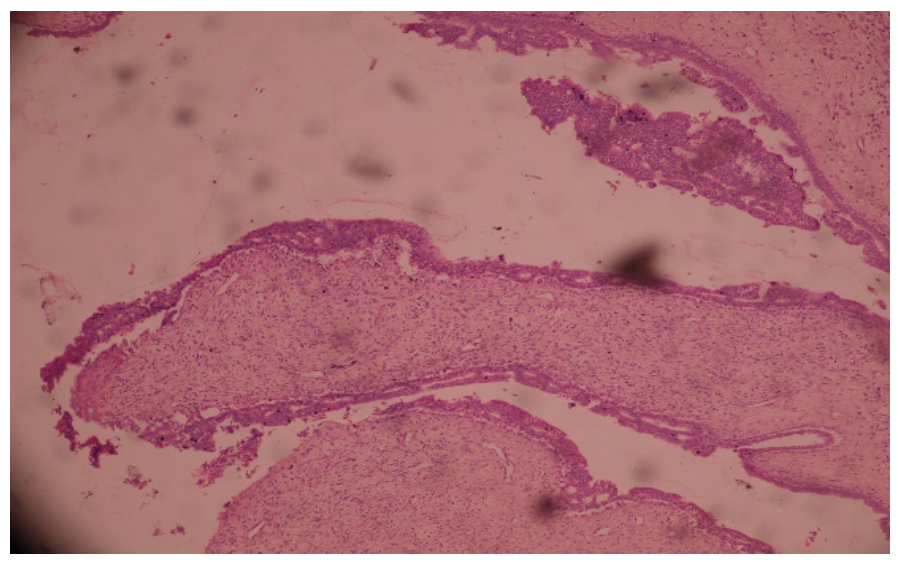

Figure-5: Phyllodes tumor

In the present study 2 cases were diagnosed as gynaecomastia and 3 cases as malignant among males. Diagnostic accuracy for gynaecomastia and malignancy in males was $100 \%$.It was reported that, the success of cytodiagnosis was varied according to histologic subtypes [8-13].

FNAC tend to be inadequate and false negative in case of duct carcinoma of schirrous subtype. The main cause for inadequate smears may be due to lack of technical experience in performing FNA, preparation. FNA of ill defined masses like lesion or lesions with hyalinization and deeply situated lumps may also be contributed to the inconclusive diagnosis [14-16]. The Figures 1 and 2 are showing the Fibroadenoma and Figures 3 and 4 shows IDC from FNAC and Biopsy examination. Figure 5 shows the biopsy of Phyllodes tumour. 
False positive diagnosis is always interpretation errors [17]. They are highly undesirable, but in large volume institutions, they will occur from time to time in the process of evaluation of rare lesion, diagnostic pitfalls and look alike such as some fibroadenomas with myoepithelial hyperplasia, complex sclerosing lesions and sclerosing adenosis. False positive diagnosis should be avoided because mastectomy or other treatments may in certain centres be performed based entirely on FNA cytologic findings [18]. False positive case can be diagnosed as suspicious for malignancy on cytology which further underwent simple mastectomy and histopathologically was diagnosed as sclerosing adenosis. Sclerosing adenosis cannot be clearly distinguished cytologically [19]. Epithelial aggregates in smears may show an obvious microacinar pattern giving rise to differential diagnostic problem, particularly with tubular carcinoma [20]. Apocrine metaplasia occurring in areas of adenosis can look extremely worrying and may be the cause of false positive diagnosis [21]. Apart from high accuracy rate of FNAC, this technique is quite attractive because of rapidity of execution and interpretation,its low cost and low rate of morbidity.

\section{Conclusion}

The FNAC of breast is cheap, safe and highly accurate method for diagnosis of breast lump preoperatively to avoid undue surgery and inconvenience during biopsy. FNAC of breast lump should be used as preliminary investigation in outdoor patient department. The same aspirated can also be used for ancillary molecular testing. FNAC shall be used as preferred diagnostic method for palpable breast lesions. True-cut needle or Excisional biopsyshall be used for confirmation.

Funding: Nil, Conflict of interest: None initiated, Permission from IRB: Yes

\section{References}

1. Hindle WH1, Payne PA, Pan EY. The use of fineneedle aspiration in the evaluation of persistent palpable dominant breast masses. Am J Obstet Gynecol. 1993 Jun;168(6 Pt 1):1814-8; discussion 1818-9.

2. Mulazim Hussain Bukhari, Madiha Arshad, Shahid Jamal, Shahida Niazi, Shahid Bashir, Irfan M. Bakhshi, and Shaharyar. Use of Fine-Needle Aspiration in the Evaluation of Breast Lumps. Patholog Res Int. 2011; 2011: 689521.

3.Rubin M, Horiuchi K, Joy $\mathrm{N}$ et al. Use of fine needle aspiration for solid breast lesions is accurate and costeffective. Am J Surg. 1997 Dec;174(6):694-6; discussion 697-8.

4. Bhaskar Thakkar, Malay Parekh, N J Trivedi, A S Agnihotri, Uravashi Mangar. Role of fine needle aspiration cytology in palpable breast lesions and its correlation with histopathological diagnosis. National Journal of Medical Research . 2014;4(4):283-288.

5. Rahman MZ, Sikder AM, Nabi SR. Diagnosis of breast lump by fine needle aspiration cytology and mammography. Mymensingh Med J. 2011 Oct;20(4):658-64.
6. Neha Amrut Mahajan, C.P Bhale, S.S Mulay. Fine Needle Aspiration Cytology of Breast Lesions and Correlation with Histopathology; A 2 Year Study. International Journal of Health Sciences \& Research. 2013;3(2);55-65.

7. Walid E. Khalbuss, M.D., Abiy Ambaye, Steve Goodison, Asif Loya, and Shahla Masood. Papillary Carcinoma of the Breast in a Male Patient With a Treated Prostatic Carcinoma Diagnosed by Fine-Needle Aspiration Biopsy: A Case Report and Review of the Literature. Diagn Cytopathol. 2006 Mar; 34(3): 214217.

8. Ascoli V, Scalzo CC, Bruno C, Facciolo F, Lopergolo M, Granone P, Nardi F. Familial pleural malignant mesothelioma: clustering in three sisters and one cousin. Cancer Lett. 1998;130(1-2):203-207.

9. Azuma K, Uchiyama I, Chiba Y, Okumura J. Mesothelioma risk and environmental exposure to asbestos: past and future trends in Japan. Int J Occup Environ Health. 2009 Apr-Jun;15(2):166-72.

10. Bani-Hani KE, Gharaibeh KA. Malignant peritoneal mesothelioma. J Surg Oncol. 2005 Jul 1;91(1):17-25.

11. Baker PM, Clement PB, Young RH. Malignant peritoneal mesothelioma in women: a study of 75 cases with emphasis on their morphologic spectrum and differential diagnosis. Am J Clin Pathol. 2005;123(5):724-737.

12. Baumann F, Rougier Y, Ambrosi JP, Robineau BP. Pleural mesothelioma in New Caledonia: an acute environmental concern. Cancer Detect Prev. 2007;31(1):70-6. Epub 2007 Feb 23.

13. Berry G, Roger J, Pooley FD. Mesotheliomas. Asbestos exposure and lung burden. In: Bignon J, Peto J, Saracci R, editors. Non occupational exposure to 


\section{Research Article}

mineral fibers. Lyon, France: 1989. pp. 486-496. IARC scientific publication No 90.

14. Hindle WH, Payne PA, Pan EY. The use of fineneedle aspiration in the evaluation of persistent palpable dominant breast masses. Am J Obstet Gynecol. 1993 Jun;168(6 Pt 1):1814-8; discussion 1818-9.

15. Lee HC, Ooi PJ, Poh WT, Wong CY. Impact of inadequate fine-needle aspiration cytology on outcome of patients with palpable breast lesions. Australian and New Zealand Journal of Surgery. 2000;70(9):656-659.

16. Khatun H, Tareak-Al-Nasir N, Enam S, Hussain M, Begum M. Correlation of fine needle aspiration cytology and its histopathology in diagnosis in breast lumpus. Bangladesh Med Res Counc Bull. 2002 Aug;28(2):77-81.
17. Nemenqani D, Yaqoob N. Fine needle aspiration cytology of inflammatory breast lesions. Journal of the Pakistan Medical Association. 2009;59(3):167-170.

18. 20. Das DK, Sodhani P, Kashyap V, Parkash S, Pant JN, Bhatnagar P. Inflammatory lesions of the breast: Diagnosis by fine needle aspiration. Cytopathology. 1992;3(5):281-289.

19. Bardales RH, Stanley MW. Benign spindle and inflammatory lesions of the breast: diagnosis by fineneedle aspiration. Diagnostic Cytopathology. 1995;12(2):126-130.

20. Guray M, Sahin AA. Benign breast diseases: classification, diagnosis, and management. Oncologist. 2006 May;11(5):435-49.

21. Lee KC, Chan JK, Gwi E. Tubular adenosis of the breast: a distinctive benign lesion mimicking invasive carcinoma. Am J Surg Pathol. 1996 Jan;20(1):46-54.

\section{How to cite this article?}

Sreedevi CH, K Pushpalatha Correlative study of FNAC and histopathology for breast lesions. Trop J Path Micro 2016;2(3):206-211.doi: 10.17511/jopm.2016.i03.21 